\title{
Psychosurgery for Obesity
}

\author{
John G. Kral \\ Department of Surgery, SUNY Downstate Medical Center, Brooklyn, NY, USA
}

Because of the current widespread performance of antiobesity surgery, more common than coronary bypass in the USA, this editorial is compulsory reading for all people treating obese patients.

The explosive increase in antiobesity surgery over the last decade [1] emanated from: i) perfection of safer, less traumatic laparoscopic surgical approaches, especially beneficial for obese patients, ii) increasing public awareness of the magnitude and severity of obesity owing to industryfunded 'infomercials' with the promise of new drugs and products (including laparoscopic circumgastric bands) and, finally, iii) broader acceptance of the research supporting a biological basis of the disease of obesity, no longer vilified as an immoral character disorder unworthy of costly cosmetic operations (except in some religious, ideological quarters).

Nevertheless, surgical treatment is still grossly underutilized. Expanded access is rejected as being an unrealistic means to curb the epidemic [2] although operations are the only methods for achieving durable medically significant weight loss with proven cardiometabolic benefit, indeed reducing mortality and adding years of improved quality of life $[3,4]$. Surgical treatment is no longer too risky or too expensive: although the upfront investment is large, it is amortized after 4 years without taking into account patient productivity [5]. No other treatment consistently delivers maintained weight loss beyond 4 years [6-8]. Just the same: all attention should be focused on prevention of obesity rather than treatment.

There are several important problematic aspects of peerreviewed publications on antiobesity surgery that must be clarified. The following attempts to address three issues. Before discussing two broad translatable problems, it is necessary to have a clear generic understanding of the most common operations.

\section{Most Common Operations}

Purely gastric restrictive procedures (e.g. adjustable circumgastric banding, gastroplasty, gastric plication) create smallvolume $(2.5-15 \mathrm{ml})$ proximal 'pouches' with small reinforced conduits into the main body of the stomach. They limit the amount of solid food that can be ingested and the rate with which such food empties from the pouch. Fast eating and poorly chewed food elicits nausea and vomiting although the intent of the operation is to cause 'satiety'. With time the pouch can enlarge (as can the distal esophagus with weakening of the lower esophageal sphincter) and the patient may adapt eating behavior exchanging soft or liquid high-caloric food for solids, e.g. avoiding meat. These operations require 'dieting', i.e. volitional control of eating and drinking. The rapid weight loss phase lasts less than 1 year [9].

Diversionary operations (e.g. gastric bypass, biliopancreatic diversion) create pouches of varying sizes connected to a loop of small bowel of varying length, bypassing the stomach, duodenum and some jejunum. They cause restriction similar to the banding operations although only transiently, usually lasting for less than 1 year. The diversionary operations alter the sequence of digestion and of absorption as well as the magnitude and timing of release of gastrointestinal peptides and enzymes, together resulting in reduced appetite. They also have aversive effects, mainly through causing discomfort from ingestion of high-caloric density soft and liquid foods rapidly emptied into the small bowel. These operations are much less dependent on volitional control or restraint and, indeed, cause greater sustained weight loss than purely restrictive procedures. The pouch and opening to small bowel stretch and the small intestinal mucosa undergoes adaptive changes depending on the proportions of intestine bypassed. These changes account for a slow gradual regain of weight after weight loss nadir (trough) has been reached, usually after 22-30 months. They have greater potential than purely restrictive operations

\begin{tabular}{ll}
\hline KARGER & @ 2009 S. Karger GmbH, Freiburg \\
Fax +497614520714 & $\begin{array}{l}\text { Accessible online at: } \\
\text { www.karger.com/ofa } \\
\text { Information@Karger.de } \\
\text { www.karger.com }\end{array}$ \\
\end{tabular}


to cause deficiencies of minerals and vitamins unless they are monitored and supplemented. However, postoperative supplementation and monitoring is much easier than treating obesity by other means than surgery.

It is critically important to recognize that these two classes of operations have significantly different effects on eating behavior over the long term, as they also have different potential for causing (preventable) side effects. One must question the ethics and the science of randomizing allocation of patients between such behaviorally different operations, just as one must question randomized comparison of surgical treatment to other forms of treatment [10].

\section{Outcome Assessment I}

It is very telling that surgeons chose the term 'bariatric surgery' for their specialty of gastrointestinal surgery. Baros is Greek for weight, and the surgeons are fixated on weight loss as their preferred measure of 'success', although it is true that patient satisfaction is highly correlated with sustained magnitude of weight loss. Before introduction of BMI as the preferred height-adjusted measure of adiposity (in the mid 1980s) actuarial tables expressed weight as 'ideal' or 'desirable' according to minimum mortality. Deviations from this nadir (often neither sex- or age-adjusted) were associated with increased prevalences of a wide array of complications. Instead of expressing postoperative weight loss in terms of percentage of preoperative body weight lost (e.g. 33\% for gastric bypass), the surgeons introduced the term 'excess weight', denoting the weight exceeding the ideal or desirable weight for height. They then expressed weight loss as percent of excess weight loss (\%EWL or PEWL; e.g. $60 \%$ for gastric bypass).

The problem with this practice, to this very day, is that they peg their definition of 'success' at a BMI $=30$ (around $120 \%$ of desirable weight), considering the inability of a patient to reduce below a BMI of 30 as 'failure'. The failure is on the part of the surgeons (and other practitioners) to recognize that any sustained voluntary weight loss is beneficial, indeed reducing mortality to age- and sex-matched 'normal-weight' population standards. A practical example: A 37-year-old woman with BMI 45 (rather typical of US surgical candidates), who has laparoscopic adjustable banding and reduces to BMI 38 sustained for 5 years is considered to be a 'failure' because she is still severely obese by WHO or any criteria although these criteria are not based on weightreduced populations [reviewed in 9]. Not only has glucose tolerance improved, blood pressure decreased and dyslipidemia been corrected, several long-term population-based studies demonstrate decreased mortality [3, 4], even for a flawed operation (open, nonadjustable banding [3]). What is consistently neglected is the fact that the chronic inflammatory overnutrition associated with excess intracellular lipid, although correlated with body weight (BMI) in untreated individuals, is actually palliated by modest weight loss. A more appropriate outcome measure might be reduction of the 'lipid accumulation product', recently demonstrated on a population level to perform better than BMI in identifying cardiovascular risk [11].

\section{Outcome Assessment II}

Operations are catabolic events - open ones, much more so than laparoscopic or endoscopic ones [12]. Weight loss, by definition, is catabolic even when it is volitional and healthy. W.B. Cannon taught us that homeostasis is a good thing, and the era of physiologic experimentation has introduced the concept of measuring during 'steady state'. Careful study of the preponderance of publications on weight loss by any modality reveals that follow-up measurements are commonly done before the patient has maintained a compensated physiological steady state during a plateau, or even worse while the patient is still losing weight (as is the case after surgery). Many of the 'mechanistic' studies aiming to understand the development of obesity through reversal of the obese state measure parameters that vary with nutritional state. Since gastrointestinal mucosal adaptation (including morphology, enzymes, molecules, secretion and absorption) affecting motility and energy balance is very effective when nitrogen balance has been achieved, measurements performed during weight loss are of questionable value.

Studies of weight loss (recognized as greater and more rapid after antiobesity operations than with other treatment [6]) should include 'stable weight' as a defined inclusion criterion (e.g. $\pm 1-2 \mathrm{~kg} / 8-10$ weeks). Remarkably this type of data is also absent in laboratory animal studies, especially 'modeling' bariatric operations. Information on patients' regain and time to and from nadir (or trough) should be presented. The safety and above all efficacy of antiobesity operations should not be evaluated based on results from patients with less than 5 years of follow-up. When this is done, the scale tips in favor of bypass procedures [13].

\section{Conclusion}

Antiobesity surgery is behavioral surgery in distinction to most other forms of surgery. In this respect restrictive operations are similar to lifestyle modification and cognitive-behavioral therapy, modalities including diet and exercise requiring control, although offering powerful negative reinforcement of rapid eating. Although chronic (homeostatic) undernutrition favors longevity in all species studied, restraint is stressful, especially in the presence of nutritive stimuli [14]. Dieting or restrained eating in women of all ages increases cortisol $[15,16]$. The cardinal difference between nonsurgical obesity treatments and diversionary or appetite regulatory operations 
(and some drugs) is the absence of restraint-induced stress after bypass surgery. This alone may explain differences between pregnancy outcomes and early-life origins of adult disease during famine (involuntary nutrient restriction) and those after maternal obesity surgery not requiring cognitive restraint (voluntary or 'programmed' undernutrition [17]).

Just as with other modalities, results are superior with more office visits. Comorbidities influence the response to surgery and weight loss by any means, counter-intuitively associated with smaller amounts of weight loss than in the absence of comorbidity [18]. Just the same, the curative effects of surgical weight loss on type 2 diabetes mellitus, hyperten- sion, sleep apnea, cardiopulmonary failure and outcome of cancer treatment are more important than the relative minor smaller amount of weight loss. The key components of any therapeutic program, whether surgical or other, are comprehensive pre-treatment evaluation and education with frequent monitoring of progress enabling further supportive education. Unfortunately this is often lacking after surgical treatment owing to surgeon disinterest and patients' erroneous belief that they have received a 'quick fix'.

Taken together, the most important preventive target of treatment of obesity is the potential of normalizing weight prior to conception.

\section{References}

1 Santry HP, Gillen DL, Lauderdale DS. Trends in bariatric surgical procedures. JAMA 2005;294: 1909-1917.

2 Kral JG: ABC of obesity. Management: part III surgery. BMJ 2006;333:900-903.

3 Sjöström L, Narbro K, Sjöström CD, Karason K, Larsson B, Wedel H, Lystig T, Sullivan M, Bouchard C, Carlsson B, Bengtsson C, Dahlgren S, Gummesson A, Jacobson P, Karlsson J, Lindroos AK, Lönroth H, Näslund I, Olbers T, Stenlöf K, Torgerson J, Agren G, Carlsson LM; Swedish Obese Subjects Study: Effects of bariatric surgery on mortality in Swedish obese subjects. N Engl J Med 2007;357:741-752.

4 Adams TD, Stroup AM, Gress RE, Adams KF, Calle EE, Smith SC, Halverson RC, Simper SC, Hopkins PN, Hunt SC: Cancer incidence and mortality after gastric bypass surgery. Obesity (Silver Spring) 2009;17:796-802.

$\checkmark 5$ Picot J, Jones J, Colquitt JL, Gospodarevskaya E, Loveman E, Baxter L, Clegg AJ: The clinical effectiveness and cost-effectiveness of bariatric (weight loss) surgery for obesity: a systematic review and economic evaluation. Health Technol Assess 2009; 13:1-190, 215-357, iii-iv

6 Bult MJ, van Dalen T, Muller AF: Surgical treatment of obesity. Eur J Endocrinol 2008;158:135-145.
7 Sacks FM, Bray GA, Carey VJ, Smith SR, Ryan $\mathrm{DH}$, Anton SD, McManus K, Champagne CM, Bishop LM, Laranjo N, Leboff MS, Rood JC, de Jonge L, Greenway FL, Loria CM, Obarzanek E, Williamson DA: Comparison of weight-loss diets with different compositions of fat, protein, and carbohydrates. N Engl J Med 2009;360:859-873.

8 Diabetes Prevention Program Research Group, Knowler WC, Fowler SE, Hamman RF, Christophi CA, Hoffman HJ, Brenneman AT, Brown-Friday JO, Goldberg R, Venditti E, Nathan DM: 10-year follow-up of diabetes incidence and weight loss in the Diabetes Prevention Program Outcomes Study. Lancet 2009;374:1677-1686.

9 Kral JG, Näslund E: Surgical treatment of obesity. Nat Clin Pract Endo Metab 2007;3:574-583.

10 Kral JG, Dixon JB, Horber FF, Rössner S, Stiles S, Torgerson JS, Sugerman HJ: Flaws in methods of evidence-based medicine may adversely affect public health directives. Surgery 2005;137:279-284.

11 Kahn HS: The 'lipid accumulation product' performs better than the body mass index for recognizing cardiovascular risk: a population-based comparison. BMC Cardiovasc Disord 2005;5:26. Erratum in BMC Cardiovasc Disord 2006;6:5.

12 Nguyen NT, Goldman CD, Ho HS, Gosselin RC, Singh A, Wolfe BM: Systemic stress response after laparoscopic and open gastric bypass. J Am Coll Surg 2002;194:557-566.
3. Guller U, Klein LV, Hagen JA: Safety and effectiveness of bariatric surgery: Roux-en-Y gastric bypass is superior to gastric banding in the management of morbidly obese patients. Patient Saf Surg 2009:3:10.

14 Libert S, Zwiener J, Chu X, Vanvoorhies W, Roman G, Pletcher SD: Regulation of Drosophila life span by olfaction and food-derived odors. Science 2007;315:1133-1137.

15 McLean JA, Barr SI, Prior JC: Cognitive dietary restraint is associated with higher urinary cortisol excretion in healthy premenopausal women. Am J Clin Nutr 2001;73:7-12.

16 Rideout CA, Linden W, Barr SI: High cognitive dietary restraint is associated with increased cortisol excretion in postmenopausal women. J Gerontol A Biol Sci Med Sci 2006;61:628-633.

17 Kral JG: Preventing and treating obesity in girls and young women to curb the epidemic. Obes Res 2004;12:1539-1546.

18 Espeland MA, Bray GA, Neiberg R, Rejeski WJ, Knowler WC, Lang W, Cheskin LJ, Williamson D, Lewis CB, Wing R; Look Ahead Study Group: Describing patterns of weight changes using principal components analysis: results from the Action for Health in Diabetes (Look AHEAD) research group. Ann Epidemiol 2009;19:701-710. 